
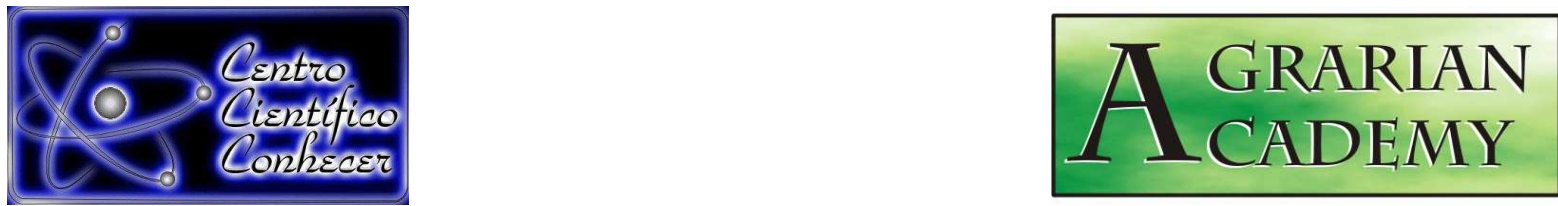

\title{
CARACTERIZAÇÃO MORFOLÓGICA DE ACESSOS DE CAGAITEIRA NA REGIÃO DE CÁCERES-MT
}

Taniele Carvalho de Oliveira ${ }^{1}$, Danilo de Lima Gonçalves ${ }^{2}$, Julio Cesar Ferreira Elias $^{3}$, Marilene Silva Castro ${ }^{4}$, Marco Antonio Aparecido Barelli ${ }^{5}$

1. Mestranda em Genética e Melhoramento de Plantas, Universidade do Estado de Mato Grosso (UNEMAT), Cáceres - MT, (tani.ele@hotmail.com).

2. Engenheiro agrônomo, Mestre, Cáceres - MT.

3. Doutorando em Agronomia na Univ. Estadual de Maringá (UEM), Maringá - PR.

4. Engenheira Agrônoma, Cáceres - MT.

5. Professor do Departamento de Agronomia e do Programa de Pós-graduação em

Genética e Melhoramento de Plantas (UNEMAT), Cáceres - MT.

Recebido em: 05/12/2014 - Aprovado em: 14/12/2014 - Publicado em: 15/12/2014

\section{RESUMO}

A cagaiteira é uma espécie arbórea, árvore frutífera natural do cerrado, que possui grande interesse econômico, principalmente por causa do aproveitamento de seus frutos na culinária, além do consumo in natura. Diante disso, o objetivo do trabalho foi avaliar a divergência genética entre acessos de cagaita por meio da caracterização morfológica na região de Cáceres-MT, selecionando 30 plantas nativas do cerrado nas proximidades da Serra da Mangaval e Morraria, avaliando o tamanho médio das folhas, tamanho médio do pecíolo, peso médio de fruto, diâmetro médio longitudinal de frutos, diâmetro transversal médio de frutos, número médio de sementes por frutos, peso médio de sementes por frutos, sólidos solúveis totais e $\mathrm{pH}$ da polpa. A divergência genética entre os acessos foi estimada a partir da Distância Euclidiana média padronizada, da análise de agrupamento mediante a utilização do método de Otimização de Tocher, e posteriormente a análise de Componentes Principais e a Importância Relativa dos Caracteres, utilizando o recurso computacional Genes e o método de Agrupamento Médio Entre Grupos (UPGMA), pelo programa computacional R. Diante dos resultados observou-se que há variabilidade genética nos acessos estudados, sendo os acessos 3, 6, 11, 23 e 24 os mais divergentes, podendo estes, serem utilizados para formação de matrizes visando futuras hibridações na tentativa de obtenção de genótipos superiores. Os caracteres peso médio de frutos, teor de sólidos solúveis totais e tamanho médio de folha foram os que mais contribuíram para a dissimilaridade total entre os 30 acessos de cagaita avaliados.

PALAVRAS-CHAVE: Análise multivariada, divergência genética, Eugenia dysenterica DC.

\section{MORPHOLOGICAL CHARACTERIZATION OF CAGAITEIRA ACCESSES IN THE REGION OF CACERES-MT}

\footnotetext{
ABSTRACT

The cagaiteira is an arboreal species, natural fruit of the tree savannah, which has great economic interest, mainly because of the use of its fruit in cooking, in addition
} 
to fresh consumption. Thus, the objective of this study was to evaluate the genetic divergence among cagaita accesses through the morphologic characterization in the region of Cáceres-MT, thirty selecting native plants of the Cerrado near the Serra da Mangaval and Morraria and evaluating the average size of leaves, average size the petiole, average fruit weight, median longitudinal diameter of fruit, average transverse diameter of fruit, average number of seeds per fruit, weight of seeds per fruit, total soluble solids and $\mathrm{pH}$ of the pulp. The genetic divergence between the lit was estimated from the Euclidean Distance standardized mean, the cluster analysis was performed by using the Tocher optimization method, then the principal component analysis and the Relative Importance of characters using the computational resource Genes and Medium grouping method Between Groups (UPGMA), the computer program $R$. in view of the results showed that there is genetic variability in the studied accesses, and the ports 3, 6, 11, 23 and 24 the most divergent, these can be used to form arrays aiming at future hybridization in an attempt to obtain superior genotypes. Characters average fruit weight, total soluble solids content and medium sized sheets were contributing the most for the total dissimilarity between 30 cagaita accesses evaluated.

KEYWORDS: Multivariate analysis, genetic divergence, Eugenia dysenterica DC.

\section{INTRODUCÃO}

A cagaiteira (Eugenia dysenterica DC.) é uma árvore frutífera natural do Cerrado, sua distribuição é bastante ampla em regiões com vegetações de cerrados e cerradões, como nos estados de Mato Grosso, Goiás, Minas Gerais e Bahia.

A espécie possui grande interesse econômico, principalmente por causa do aproveitamento de seus frutos na culinária, além do consumo in natura, sendo utilizada na fabricação de doces, geleias, licores, refrescos, sorvetes e sucos (MARTINOTTO et al., 2008). A biometria dos frutos constitui um instrumento importante para detectar a variabilidade genética dentro de populações de uma mesma espécie (CRUZ \& REGAZZI, 1994). Na predição da divergência genética são utilizados métodos biométricos analisados pela estatística multivariada, permitindo unificar múltiplas informações de um conjunto de caracteres, vários métodos multivariados podem ser aplicados, entre os quais citam-se a análise de componentes principais e métodos aglomerativos (CRUZ et al., 2012).

Dos métodos de agrupamento, os mais utilizados são os de otimização e os hierárquicos (CRUZ et al., 2011). O método de otimização de Tocher consiste na formação de grupos cujas distâncias dentro dos grupos sejam menores que as distâncias entre grupos, ao final do processo obtém-se o número de grupos e os acessos contidos em cada grupo (CRUZ \& CARNEIRO, 2003). O método de agrupamento hierárquico UPGMA, é um método de agrupamento sequencial, aglomerativo, hierárquico, sem superposições e com base na média aritmética, neste método, a distância entre dois agrupamentos é a distância média entre todos os pares de observações, um em cada agrupamento (FARIA, 2009).

A análise por componentes principais consiste em transformar um conjunto original de variáveis em outro conjunto de dimensão equivalente. Cada componente principal é uma combinação linear das variáveis originais, sendo independentes entre si e estimados com o propósito de reter, em ordem de estimação, o máximo da informação, em termos de variação total, contida nos dados iniciais (CRUZ et al., 2012).

A análise multivariada tem sido empregada tanto para características expressas por variáveis quantitativas quanto qualitativas, as quais são comumente 
utilizadas em caracterizações e avaliações da divergência genética (CRUZ \& REGAZZI, 2001). Esta técnica tem sido empregada para a quantificação da divergência genotípica e fenotípica em várias espécies nativas (SILVA, 2008; LOBẪO et al., 2011; SALOMÃO et al. 2012; LOURENÇO et al. 2013). Diante do exposto, o objetivo deste trabalho foi avaliar a divergência genética entre acessos de cagaita por meio da caracterização morfológica na região de Cáceres-MT.

\section{MATERIAL E MÉTODOS}

A coleta de dados foi realizada no município de Cáceres, localizado na região sudoeste do estado de Mato Grosso, entre as latitudes $15^{\circ} 27^{\prime}$ e $17^{\circ} 37^{\prime}$ Sul e as

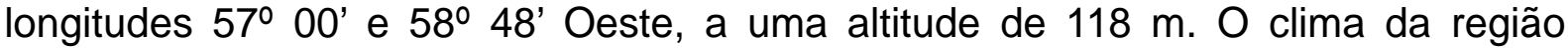
segundo classificação de Köppen é tropical quente e úmido, com inverno seco (Awa), o período de maior concentração pluvial média ocorre de dezembro a março e o período de maior estiagem ocorre de junho a agosto (NEVES et al. 2011).

Foram selecionadas 30 plantas nativas do cerrado nas proximidades da Serra da Mangaval e Morraria (Quadro 1). Para a caracterização morfológica das plantas foram avaliados 30 folhas e 30 frutos, coletando galhos de cada árvore para a avaliação de folhas e pecíolos e para a coleta dos frutos os galhos foram balançados e aparando-se os frutos de cada planta.

QUADRO 01. Localidades dos 30 acessos de cagaita coletados. Cáceres-MT, 2012.

\begin{tabular}{cccc}
\hline $\begin{array}{c}N^{\circ} \text { da } \\
\text { Planta }\end{array}$ & Localização & $\begin{array}{c}N^{\circ} \text { da } \\
\text { planta }\end{array}$ & Localização \\
\hline 1 & Chácara Alcir Monteck & 16 & Cachoeira da Peraputanga \\
2 & Chácara Alcir Monteck & 17 & Assentamento Facão \\
3 & Chácara Alcir Monteck & 18 & Assentamento Facão \\
4 & Chácara Alcir Monteck & 29 & Assentamento Facão \\
5 & Chácara Alcir Monteck & 20 & Assentamento Facão \\
6 & Chácara Alcir Monteck & 21 & Assentamento Facão \\
7 & Chácara Alcir Monteck & 22 & Assentamento Facão \\
8 & Comunidade Guanandi & 23 & Assentamento Facão \\
9 & Comunidade Guanandi & 24 & Assentamento Facão \\
10 & Comunidade Guanandi & 25 & Assentamento Facão \\
11 & Cachoeira da Peraputanga & 26 & Assentamento Facão \\
12 & Cachoeira da Peraputanga & 27 & Chácara do Eliel \\
13 & Cachoeira da Peraputanga & 28 & Serra do Mangaval \\
14 & Cachoeira da Peraputanga & 29 & Serra do Mangaval \\
15 & Cachoeira da Peraputanga & 30 & Serra do Mangaval
\end{tabular}

As características morfológicas avaliadas foram: Tamanho médio das folhas (TMF): média do comprimento longitudinal de 30 folhas por planta $(\mathrm{cm})$; Tamanho médio do pecíolo (TMP): média do comprimento de 30 pecíolos de folhas por planta $(\mathrm{cm})$; Peso médio de fruto (PMF): peso médio de 30 frutos em (g); Diâmetro médio longitudinal de frutos (DMLF): diâmetro longitudinal médio de 30 frutos colhido $(\mathrm{mm})$; Diâmetro transversal médio de frutos (DMTF): diâmetro médio transversal de 30 frutos colhido (mm); Número médio de sementes por frutos (NMSF): obtido pela média entre o número de sementes produzidas por frutos; Peso médio de sementes 
por frutos (PMSF): obtido pela média da pesagem de sementes de 30 frutos (g); Sólidos solúveis totais (SST): determinado a porcentagem de brix em refratômetro digital de leitura automática (BRIX); $\mathrm{pH}$ da polpa $(\mathrm{pH})$ : determinou-se $\mathrm{o} \mathrm{pH}$ das polpas de frutas em um pHmetro $(\mathrm{pH})$.

A divergência genética entre os acessos foi estimada a partir da Distância Euclidiana média padronizada como medida de dissimilaridade $\left(d_{i i}\right)$ : Em que $d_{i i}$ : distância entre os genótipos i e i'; $X_{i j}$ : observação no i-ésimo genitor em referência a j-ésima característica; $n$ : número de características em estudo.

A análise de agrupamento foi realizada mediante a utilização do método de Otimização de Tocher, posteriormente a análise de Componentes Principais e a Importância Relativa dos Caracteres, utilizando o recurso computacional Genes (CRUZ, 2013) e o método de Agrupamento Médio Entre Grupos (UPGMA), pelo programa computacional $R$.

\section{RESULTADOS E DISCUSSÃO}

A amplitude dos valores de dissimilaridade com base na Distância Euclidiana média foi de 0,09 a 0,72, sendo um indicativo da presença de ampla variabilidade genética entre estes acessos. A combinação entre os acessos 23 e $27\left(d_{i i^{\prime}}=0,72\right)$ foi a mais divergente, seguida pelas combinações entre 5 e $6\left(d_{i i^{\prime}}=0,66\right)$ e 3 e $6\left(d_{i i^{\prime}}=\right.$ 0,62 ), uma vez que estes pares de acessos apresentaram as estimativas mais elevadas. Entretanto, a menor divergência foi observada entre os pares 1 e $10\left(d_{i i}=\right.$ $0,09)$, bem como entre 28 e $30\left(d_{i i^{\prime}}=0,11\right)$ e 7 e $26\left(d_{i i^{\prime}}=0,13\right)$.

A análise de agrupamento dos 30 acessos pelo método de Otimização de Tocher propiciou a formação de nove grupos distintos (Tabela 1). Os grupos I e II foram os que propiciaram maior número de representantes, uma vez que juntos somam 66,67\% dos 30 acessos estudados. Os grupos III, IV e V agregaram 20,1\% dos acessos avaliados, enquanto que os grupos de VI, VII, VIII a IX foram constituídos por um acesso cada, 3, 11, 20 e 24, respectivamente.

TABELA 1. Representação do agrupamento pelo método de Otimização de Tocher com base na Distância Euclidiana média padronizada, estimada a partir de nove caracteres morfoagronômicos, dos 30 acessos de cagaita. Cáceres-MT, 2012.

\begin{tabular}{ccc}
\hline Grupos & Acessos & $(\%)$ \\
\hline I & $1,10,21,7,9,14,12,8,15,18,2,26,4$ e 29 & 46,67 \\
II & $28,30,16,13,17$ e 19 & 20,00 \\
III & 6 e 27 & 6,67 \\
IV & 5 e 25 & 6,67 \\
V & 22 e 23 & 6,67 \\
VI & 3 & 3,33 \\
VII & 11 & 3,33 \\
VIII & 20 & 3,33 \\
IX & 24 & 3,33 \\
\hline Total & 30 & $\mathbf{1 0 0}$ \\
\hline
\end{tabular}

A formação de grupo com apenas um acesso caracteriza um bom grau de divergência genética entre as plantas avaliadas, resultados semelhantes ao deste trabalho foi observado por ZUIN et al. (2009) avaliando a divergência genética entre 
43 acessos de mandioca-de-mesa (Manihot esculenta Crantz) no município de Cianorte-PR, obtiveram a formação de nove grupos distintos pelo método de Tocher, sendo os grupos VI, VII, VIII e IX com apenas um acesso cada. PUIATTI et al. (2014) avaliando a produtividade de acessos de alho por meio de características morfológicas, observaram que o método de agrupamento de Tocher dividiu os 60 acessos em oito grupos, onde os grupos VI, VII e VIII foram formados por apenas um acesso cada.

Através do método de otimização de Tocher foi possível avaliar a dissimilaridade intra e intergrupos dos acessos (Tabela 2). A maior distância média intragrupo foi observada no grupo $\mathrm{V}\left(d_{V}=0,29\right)$, enquanto que a menor distância intragrupo foi verificada no grupo III $\left(d_{I I I}=0,20\right)$. Para os grupos VI, VII, VIII e IX não foi possível estimar as distâncias intragrupos, uma vez que cada um deles foi constituído por um único acesso.

TABELA 2. Distâncias médias intra e intergrupos estimadas pelo método de Otimização de Tocher com base na Distância Euclidiana média padronizada, estimada a partir de nove caracteres morfoagronômicos, envolvendo 30 acessos de cagaita. Cáceres-MT, 2012.

\begin{tabular}{cccccccccc}
\hline $\begin{array}{c}\text { Grupo } \\
\text { S }\end{array}$ & I & II & III & IV & V & VI & VII & VIII & IX \\
\hline I & 0,24 & 0,34 & 0,47 & 0,31 & 0,34 & 0,36 & 0,31 & 0,40 & 0,32 \\
II & & 0,22 & 0,33 & 0,49 & 0,48 & 0,42 & 0,39 & 0,32 & 0,35 \\
III & & & 0,20 & 0,62 & 0,61 & 0,65 & 0,60 & 0,33 & 0,37 \\
IV & & & & 0,26 & 0,37 & 0,42 & 0,34 & 0,56 & 0,33 \\
V & & & & & 0,29 & 0,39 & 0,40 & 0,43 & 0,43 \\
VI & & & & & & - & 0,33 & 0,50 & 0,49 \\
VII & & & & & & & - & 0,50 & 0,41 \\
VIII & & & & & & & & - & 0,39 \\
IX & & & & & & & & & -
\end{tabular}

As menores distâncias intergrupos foram observadas entre os grupos I e IV $\left(d_{l: I V}=0,31\right)$, bem como entre os grupos I e VII $\left(d_{I: V I I}=0,31\right)$. Por sua vez, as maiores distâncias intergrupos foram observadas entre os grupos III e IV $\left(d_{I I I: I V}=0,62\right)$, e nos grupos III e $V\left(d_{I I ! V}=0,61\right)$, senso assim, a hibridação entre matrizes dos acessos alocados no grupo III:V (grupos mais divergentes), tenderiam a proporcionar ganhos superiores àqueles resultantes do cruzamento entre acessos do grupo I:IV e I:VII (grupos menos divergentes).

Através do método de agrupamento hierárquico UPGMA (Figura 1), submetido ao corte de $28 \%$ de distância genética e significativa pelo programa estatístico GENES, possibilitou a formação de nove grupos distintos, sendo o grupo I formado pelos acessos 3,17, 16, 28 e 30, tendo como principal característica maior PMSF e menor TMP. O grupo II é formado pelos acessos 6 e 27, apresentando maior $\mathrm{pH}$ e menor PMF. O grupo III alocou os acessos 19 e 20 por apresentarem maior NMSF e menor DMTF.

Os grupos IV, V, VI e VII foram constituídos por apenas um acesso cada, apresentando maior PMF, DMLF, SST e TMF e menor pH, TMF, DMLF e NMSF, respectivamente. O grupo VIII é formado pelos acessos 5, 25, 7 e 26, tendo como principal característica maior TMP e menor SST. O grupo IX foi o mais numeroso 
alocando 13 acessos, sendo o mais expressivo entre os nove grupos formados, apresentando maior DMTF e menor PMSF.

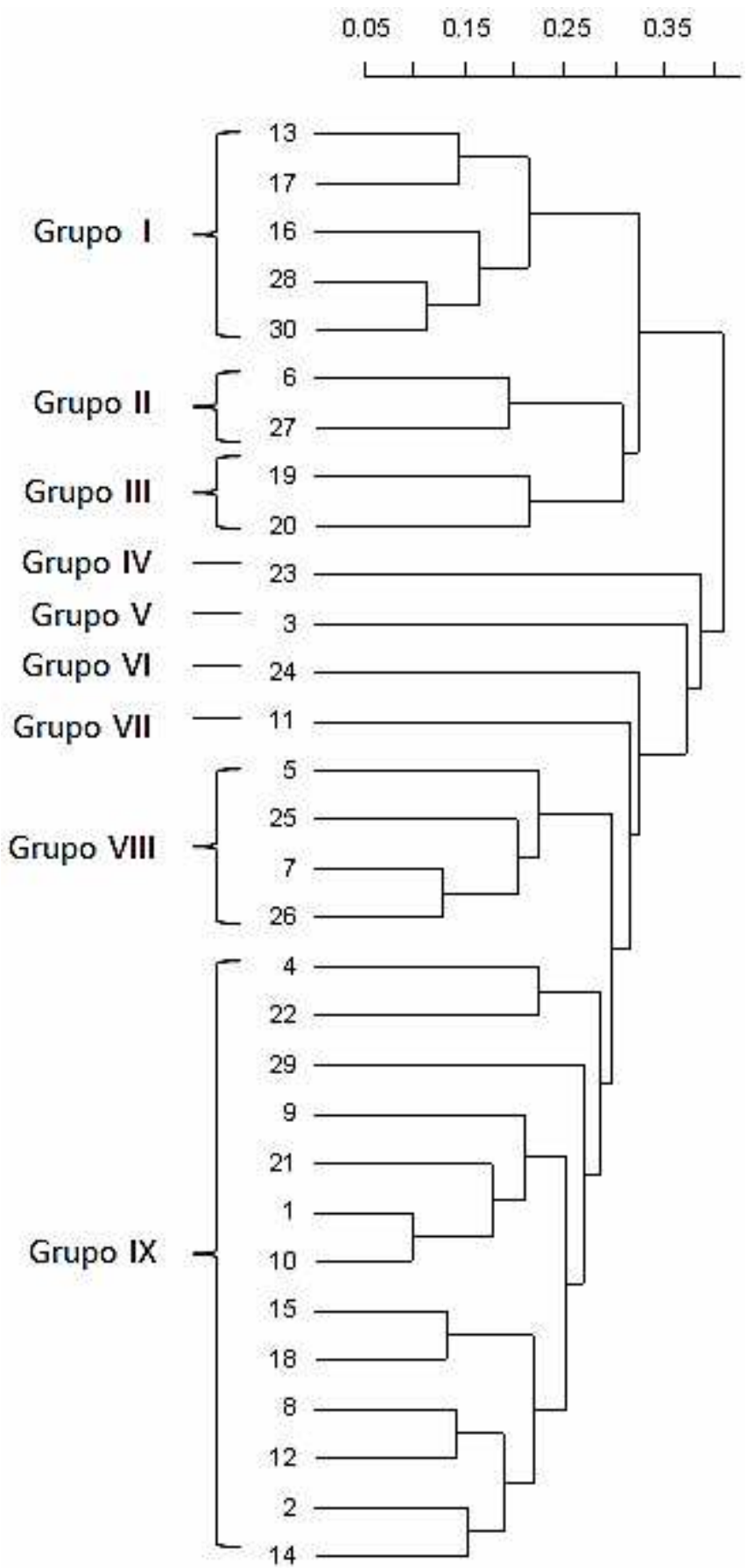

FIGURA 1. Dendrograma representativo da dissimilaridade genética entre 30 acessos de cagaita, obtido pelo método hierárquico de Agrupamento Médio Entre Grupos (UPGMA), utilizando a distância de Euclidiana Média Padronizada como medidas de dissimilaridade.

De modo geral, as combinações dos acessos que se mostraram mais similares foram entre os acessos 28 e 30 e entre os acessos 1 e 10. As combinações que apresentaram maior divergência genética foram dos acessos 23 e 3, 24 e 11, e 29 e 5. Ambos os métodos de agrupamento demonstraram semelhança 
quanto ao número de grupos formados, porém os grupos não são idênticos na disposição dos acessos, podendo ser observado nos grupos VI, VII e IX do método Tocher, os quais são formados pelos mesmos acessos dos grupos V, VI e VII do método UPGMA. Resultados semelhantes foram observados por CAMPOS et al. (2010) ao caracterizarem e quantificarem a divergência genética entre 53 acessos de mandioca no município de Cáceres-MT, observaram semelhança na formação dos grupos entre os métodos de agrupamento. GOMES FILHO et al. (2010) avaliando a divergência genética entre seis cultivares e 19 acessos de goiabeiras, por meio de marcadores moleculares RAPD e características morfoagronômicas no município de Bom Jesus do Itabapoana-RJ, observaram concordância parcial entre os métodos de agrupamentos estudados, com a formação de 12 grupos.

O coeficiente de correlação cofenética (CCC), aplicado aos métodos de agrupamento pelo teste $t$, observou-se valores significativos para o método de agrupamento médio entre grupos (UPGMA), com $(r \geq 0,65)$ e significativo $(P \leq 0,01)$ com ajuste satisfatório, demonstrando confiabilidade na relação entre a matriz de dissimilaridade e o dendrograma gerado pelo UPGMA.

Com base na análise dos componentes principais pode-se observar que houve divergência genética entre os acessos de cagaita estudados (Tabela 3). Os resultados mostram que os dois primeiros componentes explicaram cerca de $94,68 \%$ da variação total, sendo que o CP1 foi responsável por 83,78\% e o CP2 por 10,91\%, adequando-se neste caso, a uma representação gráfica bidimensional (Figura 2). Resultados semelhantes ao deste trabalho foram observados por ROCHA et al. (2013) avaliando a qualidade de néctares de goiaba light de diferentes marcas comercializadas em Lavras-MG, os autores observaram que os dois primeiros componentes principais explicaram cerca de $84,08 \%$ da variação total. Segundo CRUZ et al. (2012) a análise de componentes principais é utilizada quando os primeiros componentes envolvem pelo menos $80 \%$ da variação total, possibilitando a avaliação da importância de cada caráter estudado sobre a variação total disponível entre os genótipos avaliados.

TABELA 3. Autovalores e autovetores associados a nove caracteres morfoagronômicos em 30 acessos de cagaita. Cáceres-MT, 2012.

\begin{tabular}{ccc}
\hline Componentes Principais & Raiz (\%) & \% Acumulada \\
\hline DMTF & 83,78 & 83,78 \\
DMLF & 10,91 & 94,68 \\
NMSF & 2,72 & 97,41 \\
TMP & 1,11 & 98,52 \\
pH & 0,92 & 99,44 \\
PMSF & 0,22 & 99,66 \\
TMF & 0,16 & 99,82 \\
SST & 0,11 & 99,93 \\
PMF & 0,07 & 100,00 \\
\hline
\end{tabular}

No gráfico de dispersão dos genótipos, elaborado com base nos dois primeiros componentes principais, dispostas no espaço bidimensional (Figura 2), observa-se a formação de oito grupos. O grupo I formado pelos acessos: 27 e 6, os grupos II, VI, VII e VIII foram formados por apenas um acesso cada 30, 3, 23 e 5, respectivamente. 
Os grupos III e $\mathrm{V}$ foram os mais numerosos, sendo o grupo III composto pelos acessos 20, 13, 28, 16, 19, 8 e 24, e o grupo $V$ pelos acessos 11, 22, 21, 12, 2, 15, $10,1,9,18,7,29,26,14$ e 25. Já o grupo IV é formado por apenas dois acessos 17 e 4. De acordo com a análise os acessos similares foram ordenando em grupos semelhantes, identificando e isolando os mais divergentes em grupos distintos, indicando grande divergência genética entre os 30 acessos de cagaita.

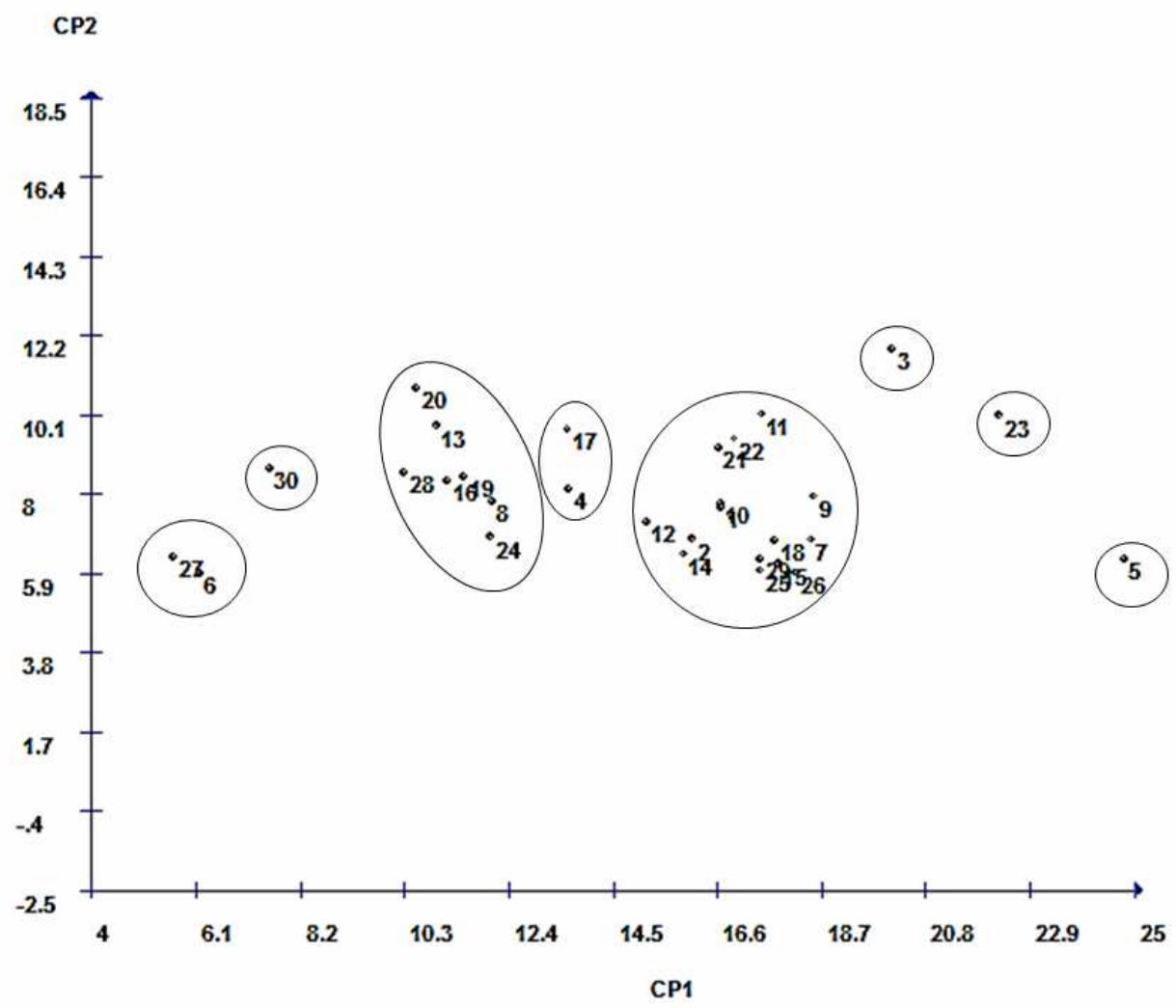

FIGURA 2. Dispersão gráfica dos escores em relação aos eixos representativos dos dois primeiros componentes principais (CP1 e CP2), dos nove caracteres morfoagronômicos, em 30 acessos de cagaita. Cáceres-MT, 2012.

A análise para estimar a contribuição relativa de cada característica para a expressão da divergência genética de acordo com o método de SINGH (1981) indicou que os caracteres PMF $(78,49 \%)$, SST $(11,67 \%)$ e TMF $(4,43 \%)$ foram os que mais contribuíram para a divergência total entre os 30 acessos de cagaita avaliado, somando $94,59 \%$ de toda a contribuição (Tabela 4). 
TABELA 4. Contribuição relativa percentual de nove caracteres morfoagronômicos avaliados para divergência $\left(d_{i i}\right)$ entre 30 acessos de cagaita. CáceresMT, 2012.

\begin{tabular}{crc}
\hline Caracteres Avaliados & \multicolumn{1}{c}{ S. j } & Contribuição (\%) \\
\hline TMP & 66,43 & 0,32 \\
TMF & 927,82 & 4,43 \\
PMF & 16454,31 & 78,49 \\
DLMF & 109,14 & 0,52 \\
DTMF & 143,34 & 0,68 \\
NMSF & 39,53 & 0,19 \\
PMSF & 553,80 & 2,64 \\
SST & 2447,07 & 11,67 \\
pH & 221,45 & 1,06 \\
\hline
\end{tabular}

Estes resultados evidenciam a importância do peso médio de fruto e do teor de sólidos solúveis totais na discriminação dos acessos, indicando que estes caracteres não devem ser descartados de futuras avaliações. MARIM et al. (2009) caracterizando a diversidade genética de acessos de tomateiro do Banco de Germoplasma de Hortaliças da UFV (BGH-UFV) e avaliando a importância relativa de caracteres na determinação dessa diversidade, observaram que as com maiores contribuições relativas para a avaliação da diversidade dos acessos foram de massa total dos frutos, massa média dos frutos, comprimento do fruto e largura do fruto.

\section{CONCLUSÕES}

Existe uma ampla variabilidade genética nos acessos estudados, sendo os acessos 3, 6, 11, 23 e 24 os mais divergentes, podendo estes serem utilizados para formação de matrizes visando futuras hibridações na tentativa de obtenção de genótipos superiores.

Os caracteres peso médio de frutos, teor de sólidos solúveis totais e tamanho médio de folhas foram os que mais contribuíram para a dissimilaridade total entre os 30 acessos de cagaita avaliados.

\section{REFERENCIAS}

CAMPOS, A.L.; ZACARIAS, A.J.; COSTA, D.L.; NEVES, L.G.; BARELLI, M.A.A.; SOBRINHO, S.P.; LUZ, P. B. Avaliação de acessos de mandioca do banco de germoplasma da UNEMAT Cáceres - Mato Grosso. Revista Trópica, v.4, n.2, p.4454, 2010.

CRUZ, C.D.; FERREIRA, F.M.; PESSONI, L.A. Biometria aplicada ao estudo da diversidade genética. Visconde do Rio Branco: Suprema, 2011. 620p.

CRUZ, C.D. GENES - a software package for analysis in experimental statistics and quantitative genetics. Acta Scientiarum. v.35, n.3, p.271-276, 2013.

CRUZ, C.D.; CARNEIRO, P.CS. Modelos biométricos aplicados ao melhoramento genético. Viçosa: UFV, 2003. $585 \mathrm{p}$ 
CRUZ, C.D.; REGAZZI, A.J. Modelos biométricos aplicados ao melhoramento genético. Viçosa: UFV, 1994. $390 \mathrm{p}$.

CRUZ, C.D.; REGAZZI, A.J. Modelos biométricos aplicados ao melhoramento Genético. Viçosa: UFV, 390 p., 2001.

CRUZ, C. D.; REGAZZI, A. J.; CARNEIRO, P. C. S. Modelo biométrico aplicado ao melhoramento genético. Viçosa: UFV, 2012. v.1, 514 p.

FARIA, P.N. Avaliação de métodos para determinação do número ótimo de clusters em estudo de divergência genética entre acessos de pimenta. 2009. 54 p. Dissertação (Mestrado em Estatística Aplicada e Biometria) - Universidade Federal de Viçosa, Viçosa, MG.

GOMES FILHO, A.; OLIVEIRA, J.G.; PIO VIANA, A.; SIQUEIRA, A.P.O.; OLIVEIRA, M.G.; PEREIRA, M. G. Marcadores moleculares RAPD e descritores morfológicos na avaliação da diversidade genética de goiabeiras (Psidium guajava L.). Acta Scientiarum, v.32, n.4, p.627-633, 2010.

LOBÃO, M.S., CASTRO, V.R.; RANGEL, A.; SARTO, C.; TOMAZELLO FILHO, M.; SILVA JÚNIOR, F.G.; CAMARGO NETO, L.; BERMUDEZ, M.A.R.C. Agrupamento de espécies florestais por análises univariadas e multivariadas das características anatômica, física e química das suas madeiras. Scientia Forestalis, v.39, n.92, p.469-477, 2011.

LOURENÇO, I.P.; FIGUEIREDO, R.W.; ALVES, R.E.; ARAGÃO, F.A.S.; MOURA, C.F.H. Caracterização de frutos de genótipos de muricizeiros cultivados no litoral cearense. Revista Ciência Agronômica, v.44, n.3, p. 499-504, 2013.

MARIM B.G.; SILVA, D.J.H.; CARNEIRO, P.C.S.; MIRANDA, G.V.; MATTEDI, A.P.; CALIMAN, F.R.B. Variabilidade genética e importância relativa de caracteres em acessos de germoplasma de tomateiro. Pesquisa Agropecuária Brasileira, v.44, n.10, p.1283-1290, 2009.

MARTINOTTO, C.; PAIVA, R.; SOARES, F.P.; SANTOS, B.R.; NOGUEIRA R.C. Cagaiteira (Eugenia Desynterica DC.). Boletim técnico, Universidade Federal de Lavras, MG, n.78, p.1-21, 2008.

NEVES, S. M. A. S.; NUNES, M C. M.; NEVES, R. J. Caracterização das condições climáticas de Cáceres/MT Brasil, no período de 1971 a 2009: subsídio às atividades agropecuárias e turísticas municipais. Boletim Goiano de Geografia, v.31, n.2, p.55-68, 2011.

PUIATTI, G.A.; CECON, P.R.; NASCIMENTO, M.; NASCIMENTO, A.C.C.; FINGER, F.L.; PUIATTI, M.; SILVA, F.F.; SILVA, A.R. Comparação dos métodos de agrupamento de Tocher e UPGMA no estudo de divergência genética em acessos de alho. Revista da Estatística UFOP, v.3, 2014.

ROCHA, L.O.F.; PIMENTA, C.J.; PEREIRA, P.A.P. Avaliação das características de qualidade de néctares de goiaba light de diferentes marcas comercializadas em 
Lavras/MG. Revista Brasileira de Tecnologia Agroindustrial, v.7, n.1, p.911-921, 2013.

SALOMÃO, R.P.; SANTANA, A.C.; BRIENZA JÚNIOR, S.; GOMES, V.H.F. Análise fitossociológica de floresta ombrófila densa e determinação de espécies-chave para recuperação de área degradada através da adequação do índice de valor de importância. Boletim do Museu Paraense Emílio Goeldi Ciências Naturais, v.7, n.1, p.57-102, 2012.

SILVA, L.M. Classificação de áreas de reflorestamentos mistos usando análise multivariada, em Cotriguaçu-MT. 2008. 88 p. Dissertação (Mestrado em Ciências Florestais e Ambientais) - Universidade Federal de Mato Grosso, Cuiabá, MT.

SINGH, D. The relative importance of characters affecting genetic divergence. The Indian Journal of Genetics and Plant Breeding. V.41, p.237-245, 1981.

ZUIN, G.C.; VIDIGAL FILHO, P.S.; KVITSCHAL, M.V.; GONÇALVES-VIDIGAL, M.C.; COIMBRA, G.K. Divergência genética entre acessos de mandioca-de-mesa coletados no município de Cianorte, região Noroeste do Estado do Paraná. Semina, v.30, n.1, p.21-30, 2009. 